\title{
Do plant defenses predict damage by an invasive herbivore? A comparative study of the viburnum leaf beetle
}

\author{
Gaylord A. Desurmont ${ }^{1}$ and Anurag A. Agrawal \\ Department of Ecology and Evolutionary Biology, Cornell University, Corson Hall, Ithaca, New York 14853 USA
}

\begin{abstract}
The impact of plant defenses on insect herbivores is widely accepted, but their relative effects on oviposition choice, survival, and larval growth in preventing pest damage, especially for invasive insects, is not fully understood. Here, we examined the potential for plant defenses to reduce the economic and environmental impacts of an invasive herbivore, the viburnum leaf beetle, VLB (Pyrrhalta viburni), on Viburnum species in North America. We used a common garden with 15 host Viburnum species of North American, European, and Asian origin and evaluated oviposition preferences, twig defense against oviposition (a reaction that crushes VLB eggs), larval performance in the lab and field, and foliar damage to mature shrubs in two consecutive years. VLB oviposition preference was the strongest predictor of plant damage, with twig defense and larval performance explaining little of the defoliation patterns. In particular, we showed that VLB females evade key defenses by choosing poorly defended twigs for oviposition; assays on the 15 Viburnum species revealed that adults laid over four times more eggs on dead (undefended) twigs than on living twigs. We additionally tested the hypothesis that shrubs with a higher proportion of dead twigs are preferentially chosen for oviposition, leading to more defoliation by larvae and increased dieback in the following year. We term this the infestation feedback hypothesis. Indeed, we report consistent positive correlations between percentage dieback, oviposition, and percentage defoliation across Viburnum species, and among individuals within two species tested separately ( $V$. dentatum and $V$. opulus).

Our results demonstrate that oviposition preference plays a major role in the susceptibility of Viburnum shrubs to the invasive VLB through adults choosing high-quality species for their larvae (a strong preference-performance correlation) and avoiding well-defended twigs among preferred species. More generally, where invasive insects can avoid plant defenses and when preference and performance are positively correlated, an infestation feedback loop can lead to persistent pest problems. Because dieback weakens Viburnum defenses by providing optimal oviposition sites, we recommend that Viburnum growers mechanically remove dead twigs from susceptible shrubs at the end of the growing season, especially in the early stages of VLB colonization.
\end{abstract}

Key words: infestation feedback hypothesis; invasion ecology; landscape pest; outbreaking herbivore; oviposition behavior; plant-insect interactions; plant resistance; preference-performance relationships; Pyrrhalta viburni; viburnum leaf beetle; Viburnum spp.

\section{INTRODUCTION}

Once an invasive herbivore spreads to a new environment, and if eradication or containment is not possible, two main approaches may help in limiting the negative consequences of the invasion on natural or managed plants: (1) anticipate plant vulnerability, in terms of expected ecological and economic impact, by understanding its causes; and (2) maintain pest populations at acceptable levels of damage on susceptible hosts. The former approach requires a detailed knowledge of the ecology of the invader as it encounters and becomes

Manuscript received 27 January 2013; revised 30 July 2013; accepted 19 August 2013; final version received 15 September 2013. Corresponding Editor: A. K. Brody.

${ }^{1}$ Present address: Institute of Biology, Neuchâtel University, Rue Emile-Argand 11, Neuchâtel 2000 Switzerland. E-mail: gaylord.desurmont@unine.ch associated with native host plants (Zavaleta et al. 2001), whereas the latter requires the existence of reliable and practical management tools that can be integrated in a control program (Simberloff 2009). In this study, we used detailed ecological data to both study plant vulnerabilities and make recommendations for management of the invasive viburnum leaf beetle (VLB) (Pyrrhalta viburni Paykull).

Among ornamentals and trees, a common management practice against insect pests is planting resistant species, cultivars, or genotypes. This practice is particularly effective when completely resistant native plants are available (Herms 2002). However, plant resistance to herbivores should be evaluated on the basis of both laboratory and field experiments (Raupp et al. 1992, d'Eustachio and Raupp 2001, Held 2004). Indeed, measures of plant resistance solely based on insect performance assays under laboratory conditions leave 
out several critical components of the insect herbivore's life cycle (host location and foraging behavior, oviposition preferences, survival in presence of natural enemies, and so forth) and potential behavioral adaptations to plant defenses, both of which may alter patterns of damage under natural conditions. For example, two native host plants showing equal levels of pest susceptibility under controlled conditions may vary greatly in realized infestation and defoliation in the field if one host is highly favored for oviposition compared to the other. Oviposition decisions may encompass an assessment of which plants are highquality food for offspring (Awmack and Leather 2002), but may also entail choosing poorly defended individuals (Alyokhin et al. 2004, Handley et al. 2005, Walter et al. 2010). In the case of novel plant-insect associations created by the introduction of exotic insects, oviposition decisions may have dramatic consequences for the fitness of the herbivore (Schlaepfer et al. 2005, Sands 2008, Gripenberg et al. 2010, Harvey et al. 2010).

The viburnum leaf beetle (VLB) is a univoltine chrysomelid native to Eurasia and a major invasive landscape pest in the northeastern United States and southern Canada (Becker 1979, Majka and LeSage 2007, Weston et al. 2007). Both larvae and adults are leaf feeders restricted to plants in the genus Viburnum (Adoxacae, Dipsacales), a clade of small trees and shrubs of worldwide importance as ornamentals. In addition to the damage inflicted upon plants in managed landscapes and urban environments, VLB has devastated populations of several native Viburnum spp. in natural habitats (e.g., forest understories, old fields, and wetlands) (Weston and Hoebeke 2003). Shrubs defoliated by larvae in the spring often produce a second flush of leaves in the weeks following defoliation, but heavily infested shrubs may not fully recover, resulting in twig and branch dieback. After 2-4 years of repeated defoliation, shrubs often die (Weston et al. 2007). The loss of Viburnum shrubs in North American forests may have dramatic ecological consequences, in particular for animals using the fruits of native Viburnum species as an important food source (Parrish 1997).

Recent research has shed light on several aspects of VLB ecology in its native and invasive range. Females lay eggs in masses (about eight eggs) in round cavities excavated through the bark within the pith of terminal Viburnum twigs and are covered with a frass-like secretion (Fig. 1). This oviposition behavior protects eggs (the overwintering stage) from desiccation and natural enemies during winter (Hilker 1992). Nonetheless, egg-infested twigs can produce a callous tissue, called wound response, that expels or crushes VLB eggs in the weeks following oviposition (Fig. 1) (Desurmont and Weston 2011). This twig defense, positively correlated with twig diameter, has been shown to be a key predictor of egg survivorship in the field. Because heavily infested twigs often die, however, they can become defenseless to subsequent oviposition events
(Desurmont et al. 2009). Thus, the extent to which twig defense plays a role in VLB invasion success in North America is unresolved. However, a phylogenetic field experiment showed that the defensive capacity of North America Viburnum spp. is considerably decreased compared to their Eurasian relatives (Desurmont et al. 2011). In addition, VLB oviposition preferences were shown to be based on the host nutritional quality for larvae (percentage foliar nitrogen) rather than on shared evolutionary history. Thus, high-quality North American Viburnum spp. are being readily attacked. The combination of adaptive choices on poorly defended hosts and the relative lack of effective natural enemies in the introduced range (Desurmont and Weston 2008) together may have created ecological conditions favorable to the VLB as an outbreaking pest in North America (Desurmont et al. 2012).

Based on our observations of VLB behavioral ecology, we hypothesize that VLB infestation patterns in its introduced range can be explained by a positive feedback between oviposition preference, insect damage, and twig dieback. This hypothesis, here named the "infestation feedback hypothesis," has the potential to be quite general, and posits that host plant species, cultivars, or genotypes that are initially favored for oviposition will suffer higher levels of defoliation by larvae and consequently greater levels of dieback. In turn, if dieback reduces resistance to oviposition or directly increases attractiveness to adults during the next oviposition period, greater infestation and defoliation by larvae will occur, facilitating a positive feedback cycle. The outcome of this feedback is that infestation and damage may escalate yearly on the same shrubs. Conversely, host plants that are initially not favored for oviposition may suffer little impact in the presence of the pest, at least in the early stages of colonization.

We tested the infestation feedback hypothesis using two years of observations and experiments in a common garden containing 15 Viburnum species of North American, European, and Asian origin (Table 1). We specifically asked the following questions. (1) How well do oviposition preference, twig defense, and larval performance predict patterns of plant damage by VLB in the field? (2) Do VLB females evade twig defenses by actively choosing poorly defended (i.e., thinner or dead) twigs for oviposition? (3) Is the infestation feedback hypothesis supported across 15 Viburnum species and among individuals of two abundant species ( $V$. dentatum and $V$. opulus)? (4) How do our data on plant resistance and insect behavior across the life cycle translate to recommendations for Viburnum growers and landscape managers?

\section{Material and Methods}

\section{Study site and insect and plant material}

All plant material used in the study originated from a common garden, composed of 386 Viburnum shrubs belonging to 29 species and ornamental hybrids, located 

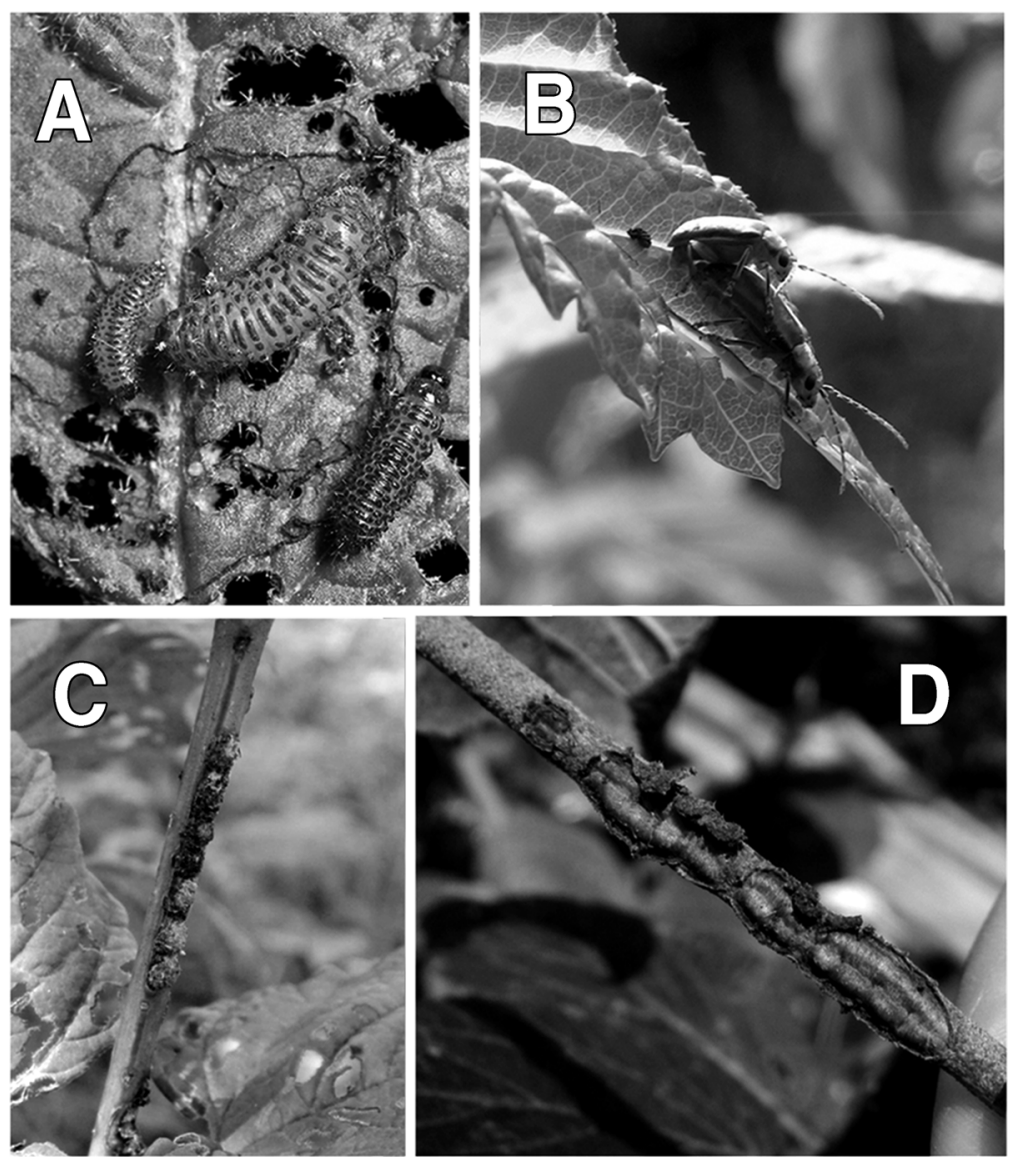

FIG. 1. Viburnum leaf beetle (VLB), Pyrrhalta viburni, (A) larvae, (B) adults, and (C) egg masses, as well as (D) twig defense (wound response) against VLB oviposition. Photo credits: Kent Loeffler (Cornell University) (A) and Gaylord Desurmont $(\mathrm{B}, \mathrm{C}, \mathrm{D})$.

in the Ithaca area (New York, USA). All 15 species used in the study (Table 1) were represented by at least four shrubs, except $V$. macropcephallum and $V$. sieboldii (two shrubs each). Shrubs were mature (8-10 years old) and had not been treated with insecticides in the last three years. Breeding populations of VLB have been reported at the study site since 2001. VLB larvae used for the insect performance assays (summer 2009) originated

TABLE 1. List of Viburnum species used in the study, with origin and percentage defoliation (mean \pm SE) by viburnum leaf beetle larvae observed in 2009 and 2010 in a common garden setting in Ithaca, New York, USA.

\begin{tabular}{|c|c|c|c|c|}
\hline \multirow[b]{2}{*}{ Species name } & \multirow[b]{2}{*}{ Common name } & \multirow[b]{2}{*}{ Origin } & \multicolumn{2}{|c|}{ Defoliation (\%) } \\
\hline & & & 2009 & 2010 \\
\hline 1) $V . \times$ bodnantense Aberc. ex Stearn & Bodnant viburnum & Asia $\dagger$ & $0.5 \pm 0.0$ & 0.0 \\
\hline 2) V. carlesii Hemsl. & Koreanspice viburnum & Asia & $1.4 \pm 0.5$ & $0.2 \pm 0.1$ \\
\hline 3) $V$. dentatum L. & arrowwood viburnum & North America & $87.4 \pm 3.1$ & $29.3 \pm 4.4$ \\
\hline 4) V. lantana L. & wayfaring tree & Europe & $4.5 \pm 0.6$ & $1.8 \pm 0.4$ \\
\hline 5) $V$. lentago L. & nannyberry viburnum & North America & $1.1 \pm 0.2$ & $0.3 \pm 0.1$ \\
\hline 6) V. macrocephalum & Chinese snowball viburnum & Asia & $7.5 \pm 2.5$ & $0.25 \pm 0.2$ \\
\hline 7) V. opulus L. & European cranberrybush & Europe & $64.0 \pm 8.3$ & $16.4 \pm 2.8$ \\
\hline 8) V. plicatum $\mathrm{f}$. tomentosum Thunb. & doublefile viburnum & Asia & $0.2 \pm 0.1$ & 0.0 \\
\hline 9) $V$. prunifolium L. & blackhaw viburnum & North America & $3.9 \pm 1.9$ & $0.9 \pm 0.2$ \\
\hline 10) V. rafinesquianum Shult. & Rafinesque viburnum & North America & $25.5 \pm 9.4$ & $1.3 \pm 0.4$ \\
\hline 11) V. rhytidophyllum Hemsl. & leatherleaf viburnum & Asia & 0.0 & 0.0 \\
\hline 12) V. sargentii Koehne & Sargent viburnum & Asia & $36.2 \pm 8.3$ & $4.0 \pm 0.7$ \\
\hline 13) V. setigerum Hance & tea viburnum & Asia & $1.2 \pm 0.2$ & $0.4 \pm 0.1$ \\
\hline 14) V. sieboldii Miq. & Siebold viburnum & Asia & $0.7 \pm 0.2$ & 0.0 \\
\hline 15) V. trilobum (=V. opulus va1 & American cranberrybush & North America & $32.0 \pm 22.7$ & $58.2 \pm 19.0$ \\
\hline
\end{tabular}

$\dagger V . \times$ bodnantense is a hybrid whose parents, V. farreri and V. grandiflorum, are both of Asian origin. 
from egg masses collected at the study site. Eggs were kept in petri dishes with a moistened filter paper until they hatched. Adults used for the evaluation of twig defense against VLB oviposition (manipulative field experiment) were collected on site in June and July 2009 and were kept on fresh $V$. dentatum and $V$. opulus shoots in plastic containers $(30 \times 22 \times 10 \mathrm{~cm})$ with a screen lid at $22^{\circ} \mathrm{C}$ and under a 15:9 (L:D) light regime until needed for experimental purposes.

\section{Predictors of VLB damage}

VLB field damage was measured for two consecutive years (2009 and 2010) as the percentage defoliation caused by VLB larvae in the common garden. Defoliation was visually estimated as a percentage of total leaf area removed for shrubs belonging to the 15 Viburnum spp. (Table 1). On average, we sampled $14.6 \pm 4.2$ shrubs per species per year (all values reported as mean $\pm \mathrm{SE}$ ), although the minimum was two shrubs for $V$. sieboldii and $V$. macrocephallum. Three main variables were evaluated as predictors of VLB damage for all species: oviposition preference, twig defense, and larval performance (analyses with JMP v. 9, general linear models; SAS Institute 2010). For each predictor, individual measures were averaged for species means, which were the data used in all analyses. Data were square-root transformed when needed to meet the assumptions of the model.

Oviposition preference.-Natural levels of oviposition were measured as the average number of eggs per twig for a random sample of terminal twigs collected for each species at the end of the growing season in 2008 and 2009 (110.1 \pm 21.0 twigs sampled per species and per year, minimum 30 for $V$. carlesii in 2008). The following parameters were measured for each twig: length, diameter, number of intact egg masses, number of egg masses encased in wound tissue, and twig vitality (alive or dead). The vitality of twigs was gauged by the presence of green tissue under the bark or buds. If a twig possessed green tissue at both ends, it was considered alive. If an infested twig possessed green tissue on the portion basal to the egg masses, but no green tissue on the distal portion, it was considered killed by VLB oviposition. Finally, if a twig presented no traces of green tissue at either end, regardless of the position of VLB egg masses, it was considered dead due to a cause other than VLB oviposition. We refer to this last category as dead twigs in the rest of the paper. The total number of dead twigs observed for a given shrub constitutes its "dieback," and percentage dieback was calculated for each shrub as the proportion of dead twigs observed in the twig sample $\times 100$.

Twig defense.-Defense against VLB oviposition was evaluated for each species by measuring the production of wound tissue in response to egg infestation, and was measured in two separate ways: oviposition observational studies (just described) during 2008 and 2009, and a manipulative field experiment during summer 2009. A subset of the results of this experiment has been reported elsewhere to test a different question (Desurmont et al. 2011). Briefly, in the manipulative field experiment, 10 terminal twigs of each Viburnum species were selected and bagged with VLB females until low (1-8 egg masses) or high ( $>14$ egg masses) egg densities were reached (five twigs per density treatment). Females were then removed from the bags to avoid further oviposition. The number of egg masses encased in wound tissue was measured for each twig at the end of the growing season (October 2009), and wound response was calculated as the percentage of encased egg masses divided by the number of egg masses initially present on the twig. In addition, a set of 15 twigs per species was artificially damaged to emulate VLB oviposition. Percentage wound response on artificially damaged twigs was gauged at the end of the growing season (October 2009) from $0 \%$ (no wound tissue) to $100 \%$ (wound tissue completely closing the damage). All of the measures of plant defense were then screened for significant correlations (JMP 9, Pearson correlations); the most representative indicator of twig defense was selected to be included in the final model.

Insect performance.-During summer 2009, a complete evaluation of VLB performance under laboratory and field conditions on all Viburnum species included in this study was conducted. A subset of the results of these experiments has been reported elsewhere to test a different question (Desurmont et al. 2011). The following indicators of insect performance were measured: larval survivorship and adult (male and female) mass. In the laboratory, newly hatched larvae were placed with young Viburnum shoots (10 measures/species) in cylindrical plastic containers with a vented lid and were monitored daily. In the field, 1-3 VLB egg masses were placed on terminal Viburnum twigs (10 measures/species) in fine-mesh nets enclosing the twigs. For both settings, a thin layer of potting mix was added to the container or bag as pupation substrate once larvae reached the final larval instar. Pupation substrate was kept under laboratory conditions once all larvae pupated, and newly emerged adults were sexed and weighed in the 24 hours following emergence. Percentage survivorship was calculated as the number of adults emerged divided by the number of larvae initially placed in the container or bag (assuming an average of eight eggs per egg mass and $100 \%$ hatching for larvae in the field). All of the performance indicators measured were then screened for significant correlations (JMP 9, pairwise correlations); the most representative indicator of performance was then selected to be included in the final model.

\section{Evasion of twig defenses}

In order to determine if Viburnum twig defense was similar in the manipulative field experiment and in the observational studies of oviposition preferences, we first compared the percentage wound response of twigs infested with low (1-8 egg masses) or high ( $>14$ egg 
masses) densities of egg masses from the observational and manipulative studies; data were analyzed using a paired $t$ test ( 1 pair $=1$ Viburnum sp., $n=15$ species) for each infestation density (JMP 9). For these tests, we used data from the 2009 observational study only because the manipulative study was also conducted in 2009 , interspersed in the same common garden. We then used data from both 2008 and 2009 observational studies to test two potential strategies of avoidance of twig defenses by VLB females: preferential oviposition onto thin twigs and preferential oviposition onto dead twigs. To determine if VLB females prefer thin twigs for oviposition, we compared the diameter of infested and noninfested twigs using a paired $t$ test ( 1 pair $=1$ Viburnum sp., $n=14$ species; $105.6 \pm 15.4$ twigs sampled per species in 2008, and $n=12,132.5 \pm 49.8$ twigs sampled per species in 2009). To determine if VLB females prefer dead twigs for oviposition, we compared the average infestation of living twigs and dead twigs using a paired $t$ test for Viburnum species whose dieback represented $>10$ twigs ( 1 pair $=1$ Viburnum sp., $n=9$ species; $266.3 \pm 75.9$ twigs sampled per species, 2009 data only). Data from 2008 observations could not be used to perform this last test because too few species had $>10$ dieback twigs sampled.

\section{Testing the infestation feedback hypothesis}

To test the infestation feedback hypothesis, we assessed correlations between percentage dieback, oviposition preferences, and percentage defoliation by larvae during two consecutive VLB annual cycles (termed cycle 1 and cycle 2), using simple correlations on species means (JMP 9). In other words, we investigated whether the amount of dieback initially present on shrubs at the beginning of cycle 1 had an effect on the following steps of the cycle (oviposition preferences by females and defoliation by larvae the following spring), and if defoliation at the end of cycle 1 had an effect on the dieback observed on these shrubs in the summer months of that year (start of cycle 2), and so on. These are not yearly cycles in the strict sense, but they correspond to the logical order of events in the infestation feedback cycle. We investigated these associations among all Viburnum species used in the study (n $=15$ species), and within individual shrubs of two wellrepresented species in our common garden: $V$. dentatum ( $n>12$ individuals) and $V$. opulus ( $n>8$ individuals). Although the analyses on individual shrubs within species have relatively low power, these analyses test a different question than that across species: specifically, whether initial differences in dieback between shrubs influenced subsequent egg loads and defoliation in the following VLB annual cycles. Finally, because the infestation feedback hypothesis is based on a priori observations and previous work, and our statistical power to address the hypotheses is limited, we adopted one-tailed tests of the predicted correlations between variables.

\section{Results \\ Predictors of VLB damage}

Summary of trait data (oviposition, twig defense, and larval performance).- The mean number of egg masses per twig (across species) was $2.3 \pm 0.6$ in 2008 and $1.2 \pm$ 0.3 in 2009 (Fig. 2). Although there was tremendous variation across species, the hierarchy of oviposition preferences across the Viburnum species was correlated across years $\left(r=0.93, F_{1,14}=91.5, P<0.0001\right)$.

The six indicators of VLB larval performance measured (percentage survivorship and male and female mass, each measured under laboratory and field conditions) were highly positively correlated (all $P<$ 0.05 for 10 out of 15 pairwise correlations, and all correlation coefficients were positive; see Appendix: Table A1). The values of laboratory and field survivorship were averaged as the measure of larval performance to be included in the final model. Similar results were obtained when other parameters of insect performance (i.e., male and female mass) were substituted for average larval survivorship.

The three indicators of twig defense (wound response at low egg density, high egg density, and to artificial damage) showed significant correlations: wound response to artificial damage was positively correlated with wound response at high density $\left(r=0.79, F_{1,11}=\right.$ 19.28, $P<0.01)$ and with the average values of wound response at high and low density $\left(r=0.66, F_{1,11}=7.55, P\right.$ $=0.02)$, but not with wound response at low density $(r<$ $\left.0.1, F_{1,14}<0.01, P=0.95\right)$. However, wound response at high density could not be measured for $V$. plicatum, $V$. rhytidophyllum, and $V$. sieboldii (thus $n=12$ species) because females never laid enough $(>14)$ egg masses on these species. Wound response to artificial damage was included in the final model as the only variable of twig defense, because it captured the greatest range of species.

$V L B$ damage is best predicted by oviposition preference.-Oviposition preferences, twig defense, and larval performance together explained $79 \%$ of the variation in VLB defoliation in 2009 (multiple regression, $R^{2}=0.79$, $\left.F_{3,13}=18.23, P<0.001\right)$, and $55 \%$ in $2010\left(R^{2}=0.55\right.$, $\left.F_{3,14}=6.84, P<0.01\right)$. In both years, oviposition preference was the only variable to significantly predict VLB defoliation $\left(F_{1,13}=29.13, P<0.0001\right.$ in $2009 ; F_{1,14}$ $=9.61, P=0.01$ in 2010). In both years, the same four species were the most preferred for oviposition and were also the most defoliated: $V$. dentatum, $V$. opulus, $V$. sargentii, and $V$. trilobum (Fig. 2). There was a significant positive correlation between oviposition preference and all indicators of larval performance except field survivorship (Appendix: Table A2), confirming previous results (Desurmont et al. 2011).

\section{Evasion of twig defenses}

Levels of twig defense are lower under natural conditions than in manipulative experiment.-The twig wound response of Viburnum species during the 2009 

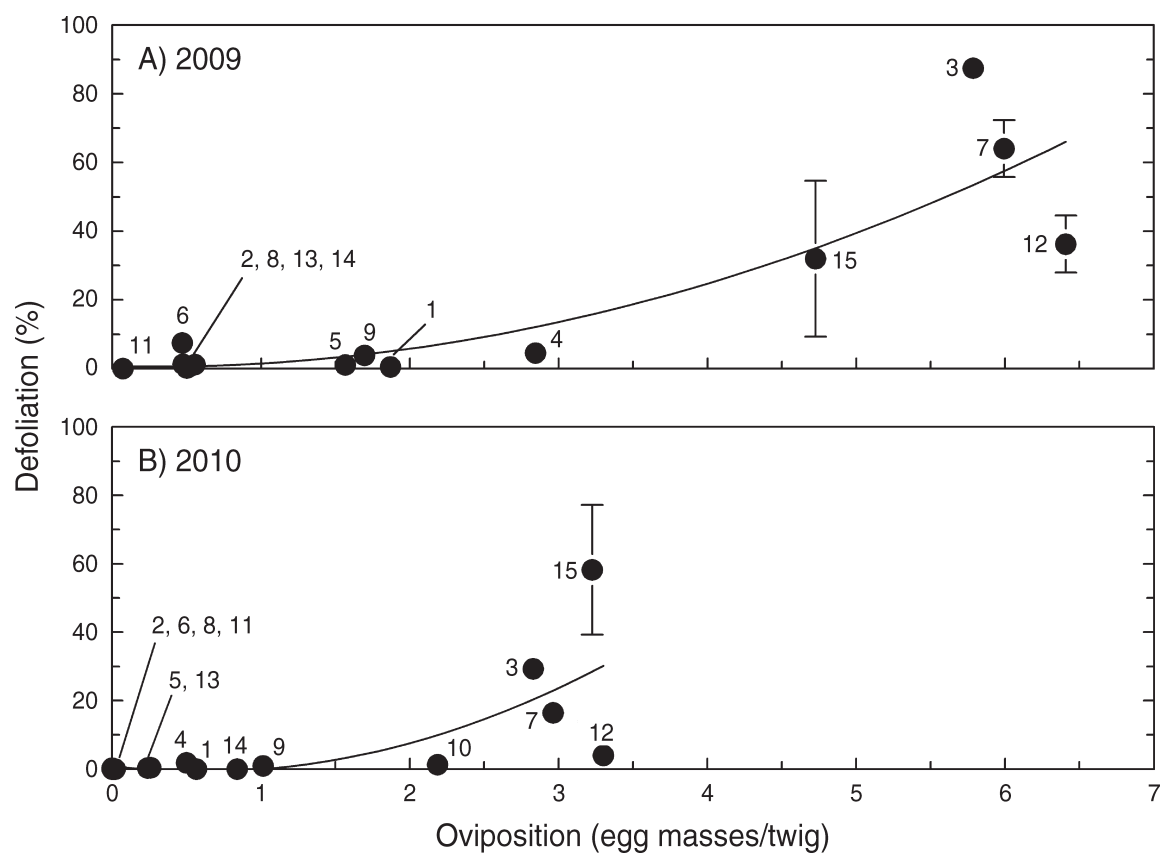

FIG. 2. Oviposition as a predictor of defoliation (mean \pm SE) in the field by VLB larvae in a common garden in (A) 2009 and (B) 2010. Defoliation is the visually estimated percentage of total leaf area removed from shrubs. Data points represent means for different Viburnum species ( $n=15$ species). Numbers refer to species' identity (Table 1). Untransformed data are shown with a polynomial fit.

observational study was consistently lower than in the manipulative study, at low egg density $(51.38 \% \pm 6.28 \%$ vs. $84.88 \% \pm 2.98 \%$, respectively; $n=15$ species, $t=6.03$, $P<0.0001)$ and high egg density $(4.46 \% \pm 3.7 \%$ vs. $53.6 \% \pm 11.5 \%$, respectively; $n=5$ species, $t=4.44, P=$ $0.01)$. This pattern was consistent for the majority of Viburnum species used (Fig. 3). Levels of twig defense were comparable in both settings only for $V$. carlesii, $V$. setigerum, and $V$. rhytidophyllum at low egg density (Fig. 3).

$V L B$ females prefer to oviposit in dead twigs, but not in twigs thinner than average.-Paired $t$ tests using the observational data from 2008 and 2009 revealed that the diameter of infested twigs was not different from the average twig diameter for all Viburnum spp. used (1.95 $\pm 0.07 \mathrm{~cm}$ vs. $1.98 \pm 0.07 \mathrm{~cm} ; n=14$ species, $t=1.18, P$ $=0.25 \mathrm{in} 2008$, and $2.34 \pm 0.10 \mathrm{~cm}$ vs. $2.38 \pm 0.09 \mathrm{~cm} ; n$ $=12$ species, $t=1.17, P=0.27$ in 2009), showing that VLB females do not prefer twigs thinner than average for oviposition. Nonetheless, dead twigs (i.e., dieback) received more than four times more egg masses $(2.49 \pm$ 0.79 masses $)$ than living twigs $(0.60 \pm 0.15$ masses $)$ across all Viburnum spp. (Fig. $4 ; n=9$ species, $t=2.73, P$ $=0.03)$. This very strong pattern of preference for dead twigs was not observed in four species ( $V$. carlesii, $V$. lentago, $V$. plicatum var. tomentosum, and $V$. setigerum), and these species were, by far, the least preferred for oviposition (less than one egg mass per four twigs overall; Fig. 4).

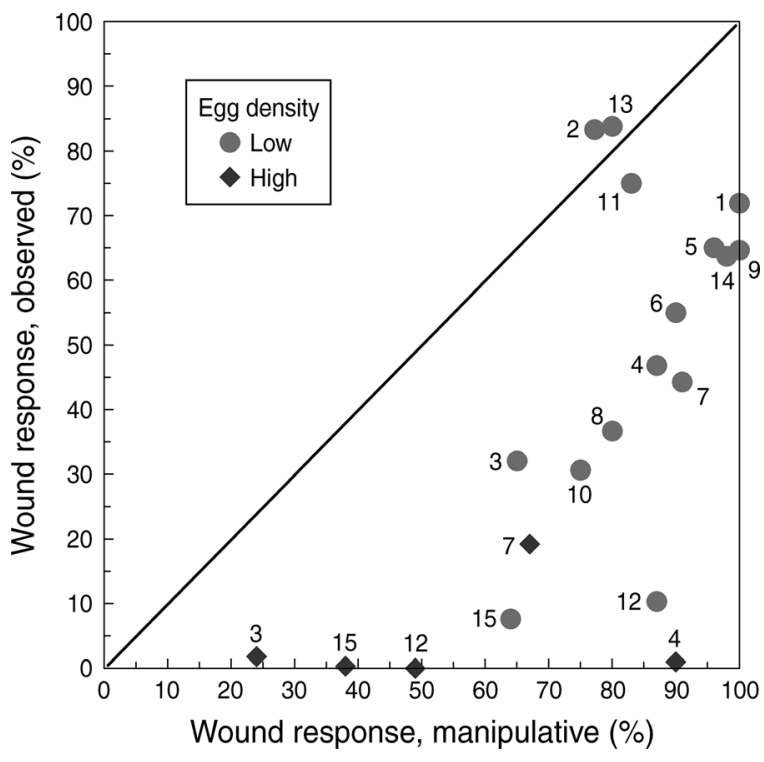

FIG. 3. Observed field values of plant defense from unmanipulated oviposition events were consistently lower than values measured in a manipulative field experiment, particularly at high egg density. Data points represent Viburnum species means ( $n=15$ species for low egg density, $n=5$ species for high egg density) for percentage of twigs showing a defensive wound response. Numbers refer to species' identity (Table 1). 


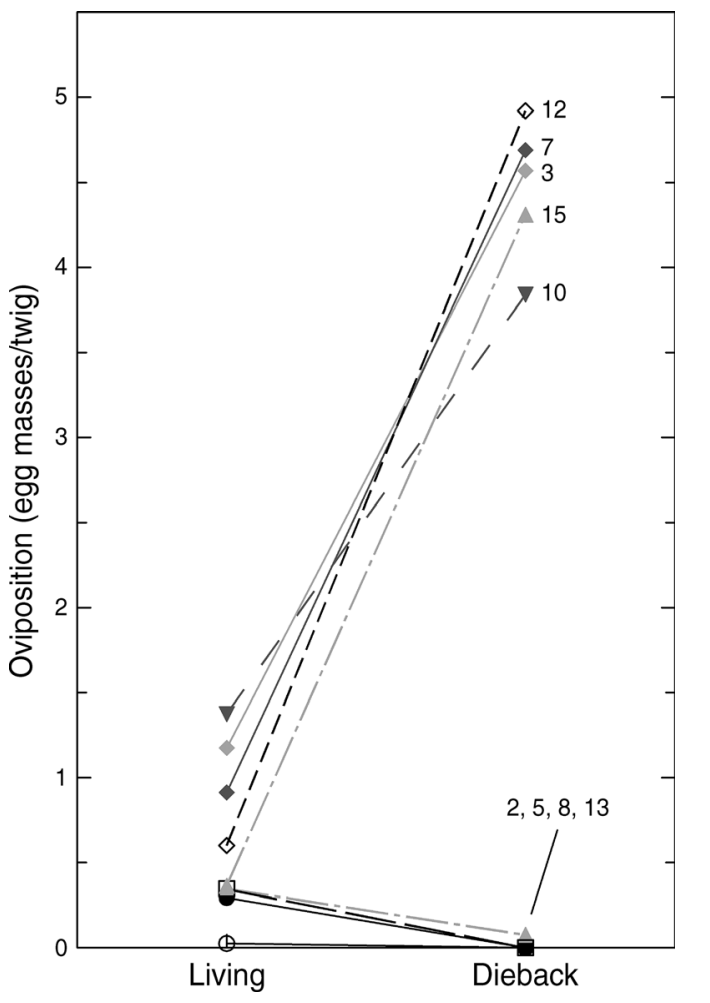

FIG. 4. Viburnum leaf beetle females lay more eggs on dead twigs (dieback) than on living twigs on species favored for oviposition ( $>0.5$ egg mass/twig, species). Data points represent Viburnum species means ( $n=9$ species). Numbers refer to species' identity (Table 1).

\section{Testing the infestation feedback hypothesis}

There were consistent positive correlations between dieback, oviposition preference, and defoliation for all Viburnum species during the two VLB annual cycles investigated (Table 2). Within individual shrubs of $V$. dentatum and $V$. opulus, all but one of these correlations were also positive (Table 2), and several of them were significant: for $V$. dentatum, oviposition preference and defoliation during both annual cycles, as well as defoliation cycle 1 and dieback cycle 2; for $V$. opulus, oviposition preference and defoliation during cycle 1, and dieback and oviposition during cycle 2 (Table 2).

\section{Discussion}

When trying to predict the effects of invading insect herbivores in novel environments, risk assessments of the vulnerability of native plants solely based on suitability assays under controlled conditions are at risk of leaving out several key components that may influence the realized impact of the pest herbivore. For example, foraging behavior and variation in feeding and/or oviposition preferences may affect which hosts get infested in the field (Dussourd and Denno 1991). Knowledge of foraging behavior, whether for food or oviposition sites, can reveal strategies by which insects avoid or cope with host defenses that would not appear under controlled conditions (Fields et al. 1990). Our study of the invasive landscape pest VLB combined manipulative evaluations of insect performance and plant defenses with two years of field observations of 15 Viburnum species in a common garden, allowing for a comprehensive approach for predicting the impact on both native and introduced ornamental Viburnum species. Our results showed that (1) oviposition preferences are the best indicator of VLB patterns of damage in the field; (2) despite the fact that several Viburnum species are highly defended against VLB oviposition (high levels of an egg-crushing wound response in twigs), VLB can largely escape this particular defense by choosing dead twigs for oviposition; and (3) twig dieback plays a critical role in initiating and reinforcing cycles of VLB damage, making management of dieback an important factor when facing VLB infestation.

The production of scar tissue in response to oviposition is lower in North American Viburnum species than in Eurasian congeners and this lower response may have contributed to VLB invasion in North America (Desurmont et al. 2011, 2012). However, our field observations show that neither variation in twig defense nor insect performance explained VLB defoliation patterns. Instead, oviposition preference was the only reliable indicator of VLB damage across both years of the study (Fig. 2). Oviposition preference was positively correlated with insect performance, confirming previous results:

TABLE 2. Test of the infestation feedback hypothesis for correlations between mean dieback, mean viburnum leaf beetle oviposition, and mean defoliation during two consecutive years for all 15 Viburnum spp. and among individual shrubs of $V$. dentatum and $V$. opulus.

\begin{tabular}{|c|c|c|c|c|c|c|c|c|c|c|c|}
\hline \multirow[b]{2}{*}{ Correlation tested } & \multicolumn{3}{|c|}{ All Viburnum spp. $(n=15)$} & \multicolumn{4}{|c|}{ V. dentatum } & \multicolumn{4}{|c|}{ V. opulus } \\
\hline & $F_{1,14}$ & $r$ & $P$ & $F$ & $\mathrm{df}$ & $r$ & $P$ & $F$ & $\mathrm{df}$ & $r$ & $P$ \\
\hline Diebacl & 13.43 & 0.7 & $<0.01$ & 1.61 & 1,11 & 0.37 & 0.12 & 0.1 & 1,7 & -0.12 & 0.38 \\
\hline Oviposition cycle $1-$ Defoliation cycle 1 & 30.64 & 0.85 & $<0.0001$ & 3.59 & 1,31 & 0.44 & 0.03 & 4.02 & 1,7 & 0.63 & 0.046 \\
\hline Defoliation cycle $1-$ Dieback cycle 2 & 11.28 & 0.68 & $<0.01$ & 19.14 & 1,43 & 0.55 & $<0.0001$ & 2.5 & 1,16 & 0.37 & 0.07 \\
\hline Dieback cycle $2-$ Oviposition cycle 2 & 25.4 & 0.81 & $<0.001$ & 0.26 & 1,44 & 0.07 & 0.3 & 5.48 & 1,16 & 0.51 & 0.03 \\
\hline Oviposition cycle $2-$ Defoliation cycle 2 & 11.3 & 0.68 & $<0.01$ & 3.71 & 1,44 & 0.28 & 0.03 & 2.06 & 1,16 & 0.34 & 0.09 \\
\hline
\end{tabular}

Notes: Mean dieback is the percentage of dead twigs/shrub; mean viburnum leaf beetle oviposition is the number of egg masses/ twig; mean defoliation is the estimated percentage of total leaf area removed from shrubs. Boldface indicates significant $P$ values $(\alpha$ $=0.05$ ) from one-tailed correlations (JMP 9). 
VLB females choose hosts based on their suitability for larval development, which is based partially on foliar nitrogen content (Desurmont et al. 2011).

Do these results mean that twig defense is unimportant in the field? We suggest "no" for two reasons. First, naturally infested shrubs do frequently show a wound response in nature, and this response can kill entire clutches of eggs (Desurmont and Weston 2011). Second, the oviposition choices and strategies of VLB appear to be shaped, at least in part, by this wound response. Not only have we shown here that VLB prefers undefended dead twigs, but also we have previously shown that native populations of VLB have locally adapted to plant species with differential twig defensive responses (Desurmont et al. 2012). Nonetheless, in the majority of Viburnum species, we observed wound responses that were dramatically lower under natural conditions (i.e., where beetles had a choice for oviposition) as compared to the results of a manipulative study, where VLB females were forced to oviposit on particular branches, especially at high egg density (Fig. 3). This suggests that VLB females may be able to avoid twig defenses by orienting their oviposition choices toward twigs with reduced capacity to produce wound tissue. Such twigs could be twigs thinner than average (Weston et al. 2008), or dead as a result of previous extensive defoliation (dieback) (Desurmont et al. 2009). VLB females indeed show a clear preference for dead twigs (Fig. 4), but not for thin twigs. Additionally, there may be other ways for VLB females to discriminate among twigs based on their defenses. When we excluded dead twigs from our observational study data, the natural levels of twig defense observed on the remaining twigs matched the levels of defense measured in the manipulative study only for a few Viburnum species: V. dentatum, V. opulus, and $V$. rafinesquianum; for most of the other species, levels of defenses remained lower compared to the manipulative study (data not shown). This suggests that VLB females may be able to avoid defenses via an alternative mechanism to the use of dead twigs.

Dead twigs represent "defense-free space" (Gandhi and Herms 2010) for ovipositing females. Because firstinstar larvae are mobile, larval survivorship may not be impacted by overwintering in dead twigs as long as living twigs bearing green leaves are present nearby. Interestingly, this preference for dead twigs was observed only on species favored for oviposition and highly suitable for VLB larvae: V. dentatum, V. opulus, $V$. rafinesquianum, $V$. sargentil, and $V$. trilobum, but was absent on species less favored for oviposition (Fig. 4).

\section{Infestation feedback hypothesis}

Overall, our observations suggested that females maximize larval survivorship by preferring highly suitable host species and less defended twigs for oviposition. This led us to formulate the "infestation feedback hypothesis," which posits that host plant species, varieties, or genotypes initially favored for oviposition will become more heavily defoliated and suffer more dieback, causing increased attractiveness for oviposition in the following year, repeating and reinforcing the cycle. We found support for this hypothesis among the 15 Viburnum species examined (Table 2). The same group of species ( $V$. dentatum, $V$. opulus, $V$. sargentii, and $V$. trilobum) was successively and consistently preferred for oviposition, was more defoliated, and suffered more dieback for the two years of the study. This result alone does not indicate a causal link between dieback and damage in the following year; however, there was a clear preference for dead twigs for oviposition across all the preferred species (Fig. 4), suggesting that the amount of dieback present on these species directly influences their final egg load at the end of the oviposition period. The exploration of these associations within individual shrubs of two common species, $V$. dentatum, and $V$. opulus, provides further support for the hypothesis (Table 2). However, the link between dieback and oviposition preference was weaker at the intraspecific level: shrubs with higher levels of dieback did not necessarily experience increased egg laying.

Several reasons may explain why we found weaker evidence for the infestation feedback hypothesis across shrubs within a single species. First, the importance of dieback for oviposition and egg survivorship may be higher at early stages of VLB colonization in a new environment. Healthy, noninfested Viburnum shrubs are expected to have low levels of natural dieback. Therefore, the amount of "defense-free space" available may be a limiting factor for VLB females in these areas, causing more pronounced preferences for shrubs with higher levels of dieback. However, our study was a snapshot of two years at a site that had been colonized by VLB eight years prior and repeatedly heavily infested since then: the level of dieback was $27.11 \%$ and $41.5 \%$ on $V$. dentatum shrubs in 2008 and 2009, and $32.6 \%$ and $53.4 \%$ on $V$. opulus shrubs in 2008 and 2009. The infestation feedback hypothesis would perhaps be better tested during the process of colonization of VLB in a new healthy Viburnum site.

Secondly, fluctuations in VLB infestation caused by external factors from year to year may not allow a steady infestation feedback to develop: in our study, despite the high levels of infestation and defoliation observed during year 1, infestation and damage did not increase in year 2. Several factors, such as the action of natural enemies or early dispersal of adults off the site, may contribute to the fluctuations in egg mass densities on Viburnum shrubs at the end of the season.

The infestation feedback hypothesis may be widely applicable where successive generations of herbivores attack the same plants (Poelman et al. 2010). Indeed, the idea that stressed plants may become more vulnerable to herbivores, leading to negative feedback for plants, has been previously proposed and discussed in the plant defense literature (Mattson and Haack 1987, Mody et 
al. 2009), but rarely in the context of applied invasion ecology (Hammons et al. 2009). We propose the use of the term "infestation feedback" in the context of plantherbivore interactions when the following conditions are met:

1) When infestation of a new host plant population occurs, some individuals, varieties, or species are more heavily attacked than others.

2) Infestation and plant damage are positively associated with attractiveness for oviposition or vulnerability to subsequent attack.

3) The same plants are preferentially attacked and defoliated in the following year or generation, accentuating the initial pattern of damage and creating a positive feedback cycle that may lead to population outbreaks and plant mortality.

The way VLB adults create self-reinforcing cycles of infestation on live shrubs is in some ways similar to host colonization by tree-killing bark beetles, which use aggregation pheromones to quickly build up high densities of attackers after the initial infestation by "pioneers," and overcome tree defenses (Raffa et al. 1993, Six and Wingfield 2011). However, the effects of tree-killing bark beetle infestations do not carry over multiple generations: they must succeed at killing their host quickly in order to complete their life cycle, as all scolytids require recently dead tissue for reproduction (Raffa et al. 1993). Thus, such infestations are rapid mass attacks, resulting in obligate host death (if infestation is successful), which contrasts with the slow, multigenerational process of the infestation feedback observed in the VLB system. Moreover, host death is not obligate in our system: VLB adults have no benefit in killing the shrubs they infest, and host death typically occurs under natural conditions only for the most susceptible Viburnum species and after suffering successive VLB outbreaks (Weston et al. 2007). As mentioned earlier, several environmental factors can impact VLB populations and may prevent the formation of outbreaks, slowing down or interrupting the feedback, and allowing infested shrubs to recover during years of low VLB populations (G. A. Desurmont, personal observations).

\section{Applications for VLB management}

The viburnum leaf beetle invasion front in North America is spreading each year. Even though the first record of this insect in North America was documented in 1924 in Nova Scotia, Canada (Majka and LeSage 2007), damaging populations were not recorded until 1978, when breeding populations of VLB were observed in Ottawa, Ontario, and Hull, Quebec, Canada (Becker 1979). Since then, VLB has steadily spread through southern Canada and the northeastern United States, as fast as 25 miles $(\sim 40 \mathrm{~km})$ per year along large bodies of water (Weston and Hoebeke 2003). It now occurs in all New England states, Maine, New York, Pennsylvania, and Ohio, devastating native and ornamental Viburnum species. Our observations of an infestation feedback in our common garden correspond to the most commonly observed pattern of VLB colonization in eastern North America (G. A. Desurmont, personal observations; P. Weston, personal communication): a quick buildup of VLB populations on susceptible shrubs in the early years following colonization of a site. Subsequent outbreaks may then occur for a few generations and result in shrub death in the case of successive complete defoliations, or in a VLB population crash due to lack of leaves. Although the ecological impact of VLB invasion has yet to be fully evaluated, especially its impact on secondary succession and on birds via depletion of Viburnum fruits, its economic impact in managed landscapes is already considerable (Weston et al. 2007). The practical value of our study for VLB management is threefold.

First, our work constitutes the most complete set of observations of VLB damage under natural conditions in a common environment, including a large number of Viburnum species. Our two-year observational study is consistent with previous observations made in the common garden since its establishment in 1999, and with a larger body of VLB damage observations realized by landscape managers and home owners in North America (summarized as a list of Viburnum species and their susceptibility to VLB at the Cornell Viburnum Leaf Beetle Citizen Science website). ${ }^{2}$ Overall, the mapleleaved species $V$. trilobum (American cranberrybush), $V$. opulus (cranberrybush), and $V$. sargentii (Sargent viburnum), as well as the North American $V$. dentatum (arrowwood viburnum) were the most susceptible species, repeatedly and frequently heavily defoliated by VLB larvae. Asian species such as $V$. carlesii, $V$. macrocephallum, $V$. plicatum var. tomentosum, $V$. setigerum, $V$. sieboldii, and the hybrid $V . \times$ bodnantense were very resistant to beetles and barely touched by adults for oviposition. Additional Asian species present in the garden but not included in the study show comparably high levels of resistance: $V$. $\times$ conoy (Conoy viburnum), $V . \times$ burkwoodii (Burkwood viburnum), $V . \times$ juddii (Judd viburnum), and $V$. rhytidophylloides (Alleghany viburnum). Among native North American Viburnum species, $V$. lentago and $V$. prunifolium were the most resistant species found in the study. More recent research suggests that $V$. acerifolium (mapleleaf viburnum) and $V$. lantanoides (hobblebush) may also show moderate to high levels of resistance to VLB (G. A. Desurmont, unpublished data).

These results should be taken as a strong indicator of Viburnum susceptibility under natural conditions, but variation in susceptibility may occur due to genotypic variation between different Viburnum varieties and cultivars. In addition, environmental conditions may directly influence resistance to VLB. For example, plants

2 http://www.hort.cornell.edu/vlb/suscept.html 
grown in the shade are known to be typically more damaged than plants grown with abundant sunlight (Weston et al. 2007). Future work would profitably address the genetic and environmental characteristics that may aid in the survival of abundant and susceptible North American natives such as $V$. dentatum and $V$. trilobum.

Secondly, our study illustrates that the presence of dieback facilitates pest infestation and defoliation by providing undefended twigs to VLB females, thus reducing the overall shrub resistance to VLB oviposition. Pruning out egg-infested twigs has been suggested as a way to mechanically control VLB infestation (Weston et al. 2007). Although labor intensive, this strategy may be facilitated by an unusually large window of time for mechanical removal, as VLB eggs lie dormant from summer to the following spring. Furthermore, mechanically removing dead twigs and branches from Viburnum shrubs before adults are abundant may further help to reduce egg deposition on shrubs at the end of the season, as well as potentially decrease the overall egg survivorship in infested twigs due to wound response. This management strategy may be particularly valuable at the early stages of VLB colonization in a new environment, when Viburnum shrubs are healthy and dieback is scarce.

Thirdly, our work could serve as a basis for future evaluations of the susceptibility of other Viburnum species to VLB. The critical importance of females' egg laying choices for realized damage makes oviposition preference assays very valuable. Because oviposition preferences and larval performance are well correlated for VLB, and because most of the indicators of performance were positively associated in our study, performance assays under controlled or field conditions may be used as a proxy for oviposition preferences. Additionally, the preference-performance correlation itself deserves to be examined at a broader scale. Finding Viburnum species, cultivars, or genotypes that show divergent preference-performance patterns (e.g., preferred for oviposition but poorly suitable for larvae) could have practical value for the development of alternative VLB management programs.

\section{ACKNOWLEDGMENTS}

We thank Paul Weston, who established the Viburnum common garden in Ithaca and supported early stages of this work; Amy Hastings, Alexis Erwin, Ellen Woods, Emily Kearney, Daisy Johnson, and Trey Ramsey, who helped with field or lab work; members of the phytophagy laboratory for discussions; and Alison Brody, Marjorie Weber, Katja Poveda, and anonymous reviewers for comments on the manuscript. This work was funded by NSF DEB-1118783 and federal formula funds from USDA (Hatch project NYC-183453) to A. A. Agrawal.

\section{Literature Cited}

Alyokhin, A. V., P. J. Yang, and R. H. Messing. 2004. Oviposition of the invasive two-spotted leafhopper on an endemic tree: Effects of an alien weed, foliar pubescence, and habitat humidity. Journal of Insect Science 4:13.
Awmack, C. S., and S. R. Leather. 2002. Host plant quality and fecundity in herbivorous insects. Annual Review of Entomology 47:817-844.

Becker, E. C. 1979. Pyrrhalta viburni (Coleoptera-Chrysomelidae), a Eurasian pest of Viburnum recently established in Canada. Canadian Entomologist 111:417-419.

Desurmont, G. A., M. J. Donoghue, W. L. Clement, and A. A. Agrawal. 2011. Evolutionary history predicts plant defense against an invasive pest. Proceedings of the National Academy of Sciences USA 108:7070-7074.

Desurmont, G. A., C. M. Fritzen, and P. A. Weston. 2009. Oviposition by Pyrrhalta viburni (Paykull) on dead plant material: successful reproductive strategy or maladaptive behavior? Pages 115-125 in P. Jolivet, J. A. Santiago-Blay, and M. Schmitt, editors. Research on Chrysomelidae. Volume 2. Brill, Leiden, The Netherlands.

Desurmont, G. A., F. Hérard, and A. A. Agrawal. 2012. Oviposition strategy as a means of local adaptation to plant defence in native and invasive populations of the viburnum leaf beetle. Proceedings of the Royal Society B 279:952-958.

Desurmont, G. A., and P. A. Weston. 2008. Predation by Podisus maculiventris (Say) (Hemiptera: Pentatomidae) on viburnum leaf beetle, Pyrrhalta viburni (Paykull) (Coleoptera: Chrysomelidae) under laboratory and field conditions. Environmental Entomology 37(5):192-202.

Desurmont, G. A., and P. A. Weston. 2011. Aggregative oviposition of a phytophagous beetle overcomes egg-crushing plant defences. Ecological Entomology 36:335-343.

d'Eustachio, G., and M. J. Raupp. 2001. Resistance of boxwood varieties to the boxwood leafminer, Monarthropalpus flavus (Schrank). Journal of Environmental Horticulture 19:153-157.

Dussourd, D. E., and R. F. Denno. 1991. Deactivation of plant defense: correspondence between insect behavior and secretory canal architecture. Ecology 72:1383-1396.

Fields, P. G., J. T. Arnason, and B. J. R. Philogene. 1990. Behavioral and physical adaptations of three insects that feed on the photoxic plant Hypericum perforatum. Canadian Journal of Zoology 68:339-346.

Gandhi, K., and D. Herms. 2010. Direct and indirect effects of alien insect herbivores on ecological processes and interactions in forests of eastern North America. Biological Invasions 12:389-405.

Gripenberg, S., P. J. Mayhew, M. Parnell, and T. Roslin. 2010. A meta-analysis of preference-performance relationships in phytophagous insects. Ecology Letters 13:383-393.

Hammons, D. L., S. K. Kurtural, M. C. Newman, and D. A. Potter. 2009. Invasive Japanese beetles facilitate aggregation and injury by a native scarab pest of ripening fruits. Proceedings of the National Academy of Sciences USA 106:3686-3691.

Handley, R., B. Ekbom, and J. Agren. 2005. Variation in trichome density and resistance against a specialist insect herbivore in natural populations of Arabidopsis thaliana. Ecological Entomology 30:284-292.

Harvey, J. A., T. Bukovinszky, and W. H. van der Putten. 2010. Interactions between invasive plants and insect herbivores: A plea for a multitrophic perspective. Biological Conservation 143:2251-2259.

Held, D. W. 2004. Relative susceptibility of woody landscape plants to Japanese beetle (Coleoptera: Scarabeidae). Journal of Arboriculture 30:328-335.

Herms, D. A. 2002. Strategies for deployment of insect resistant ornamental plants. Pages 217-237 in M. R. Wagner, K. M. Clancy, F. Lieutier, and T. D. Paine, editors. Mechanisms and deployment of resistance in trees to insects. Springer, Dordrecht, The Netherlands.

Hilker, M. 1992. Protective devices of early developmental stages in Pyrrhalta viburni (Coleoptera, Chrysomelidae). Oecologia 92:71-75. 
Majka, C. G., and L. LeSage. 2007. Introduced leaf beetles of the maritime provinces, 3: the Viburnum leaf beetle, Pyrrhalta viburni (Paykull) (Coleoptera: Chrysomelidae). Proceedings of the Entomological Society of Washington 109:454-462.

Mattson, W. J., and R. A. Haack. 1987. The role of drought in outbreaks of plant-eating insects. BioScience 37:110-118.

Mody, K., D. Eichenberger, and S. Dorn. 2009. Stress magnitude matters: different intensities of pulsed water stress produce non-monotonic resistance responses of host plants to insect herbivores. Ecological Entomology 34:133-143.

Parrish, J. D. 1997. Patterns of frugivory and energetic condition in Nearctic landbirds during autumn migration. University of California Press, Berkeley, California, USA

Poelman, E. H., J. J. Van Loon, N. M. Van Dam, L. E. Vet, and M. Dicke. 2010. Herbivore-induced plant responses in Brassica oleracea prevail over effects of constitutive resistance and result in enhanced herbivore attack. Ecological Entomology 35:240-247.

Raffa, K. F., T. W. Phillips, and S. M. Salom. 1993. Strategies and mechanisms of host colonization by bark beetles. Pages 103-128 in T. D. Schowalter and G. M. Filip, editors. Beetlepathogen interactions in conifer forests. Academic Press, New York, New York, USA.

Raupp, M. J., C. S. Koehler, and J. A. Davidson. 1992. Advances in implementing integrated pest management for woody landscape plants. Annual Review of Entomology 37:561-585.

Sands, D. 2008. Conserving the Richmond birdwing butterfly over two decades: Where to next? Ecological Management and Restoration 9:4-16.
SAS Institute. 2010. JMP version 9. SAS Institute, Cary, North Carolina, USA.

Schlaepfer, M. A., P. W. Sherman, B. Blossey, and M. C. Runge. 2005. Introduced species as evolutionary traps. Ecology Letters 8:241-246.

Simberloff, D. 2009. We can eliminate invasions or live with them. Successful management projects. Biological Invasions $11: 149-157$.

Six, D. L., and M. J. Wingfield. 2011. The role of phytopathogenicity in bark beetle-fungus symbioses: a challenge to the classic paradigm. Annual Review of Entomology 56:255-272.

Walter, A. J., R. C. Venette, and S. A. Kells. 2010. Acceptance and suitability of novel trees for Orthotomicus erosus, an exotic bark beetle in North America. Biological Invasions 12:1133-1144.

Weston, P. A., G. Desurmont, and E. R. Hoebeke. 2007. Viburnum leaf beetle: biology, invasion history in North America, and management options. American Entomologist 53:96-101.

Weston, P. A., M. D. Diaz, and G. A. Desurmont. 2008. Ovipositional biology of viburnum leaf beetle, Pyrrhalta viburni (Coleoptera: Chrysomelidae). Environmental Entomology 37:520-524.

Weston, P. A., and E. R. Hoebeke. 2003. Viburnum leaf beetle, Pyrrhalta viburni (Paykull) (Coleoptera: Chrysomelidae): Dispersal pattern of a palearctic landscape pest in New York and its distribution status in the northeastern US and eastern Canada. Proceedings of the Entomological Society of Washington 105:889-895.

Zavaleta, E. S., R. J. Hobbs, and H. A. Mooney. 2001. Viewing invasive species removal in a whole-ecosystem context. Trends in Ecology and Evolution 16:454-459.

\section{Supplemental Material}

\section{Appendix}

Tables showing correlation coefficients between six indicators of viburnum leaf beetle performance measured under laboratory and field conditions on 15 Viburnum species and oviposition preference measured in the field in 2008 and 2009 (Ecological Archives A024-045-A1). 